inserted while CPR is performed. I see the heart rate slow as the resident tires: they need another set of hands. There is no one else, so I am up. The chest tubes are in, but the heart isn't beating on its own. The defibrillator is a last-ditch effort, delivering a shock: once, twice, nothing. Time of death is called, and I am still holding the bag-valve-mask.

Although all these stories are tragic, I find none more devastating than the 17-year-old boy I meet on my last day who was simply in the wrong place at the wrong time. It is 8 am on a weekday, and he is brought in with a gunshot wound to his right shoulder. His mother tells me he was walking to school when a bullet struck him out of nowhere. The chest $\mathrm{x}$-ray confirms that the bullet is lodged in the T5 vertebral segment. The resident confides that the best-case scenario is spinal shock, but she is not holding out hope. She explains what should have been obvious to me at first glance at the x-ray: the entry wound is through his right shoulder, and the bullet is sitting on the left side of his vertebral column. The bullet has likely severed his spinal cord; he will be paralyzed from $\mathrm{T} 5$ down.

The stories I am sharing here reflect a mere three nights in the trauma unit at Groote Schuur Hospital. I have seen enough trauma for three years. If my experiences there are typical, and I'm told they are, then I understand - in a way that goes beyond mortality statistics that trauma is a major, heart-breaking public health crisis. Tragically, data to describe adequately the scope and depth of this crisis barely exist. No effective systems to collect injury data are in place.

We do know that trauma is the leading cause of death among children and working-aged adults in almost every country in the world. ${ }^{1}$ We know little about what types of injuries are occurring, let alone where and why. According to the Director-General of the World Health Organization, "we must not forget that the real need is to close the data gaps, especially in low-income and middle-income countries." ${ }^{2}$ Closing these gaps may be the best way to reduce the steady flow of tragedies in trauma units around the world.

Without reliable data, trauma in South Africa will likely remain overshadowed by better-known health crises. We have data for many global health epidemics: HIV, tuberculosis and malaria, to name a few. Why have we ignored the global health pandemic that is trauma and injury?

\section{Lauren Adolph}

Class of 2016, Faculty of Medicine,

University of British Columbia,

Vancouver, BC

\section{References}

1. Farmer PE, Kim JY. Surgery and global health: a view from beyond the OR. World J Surg 2008; 32:533-6.

2. Chan M. From new estimates to better data. Lancet 2012;380:2054.

This is a true story, but pertinent details have been changed to protect the identity of patients.

CMAJ 2016. DOI:10.1503/cmaj.150711

\title{
First exposure
}

${ }^{66} \mathrm{G}$ o ahead, take a listen to her heart," the doctor said. "I'll come back in a few minutes and we'll discuss what you hear."

And we were alone. Alone with the patient, that is. Six students, uncomfortable in white coats literally too big for us, on the second day of medical school. The patient sat expectantly on the bed, waiting for one of us to approach. She wore only a hospital gown, a sterile green, of course, - some of her chest was exposed - our preceptor had (very quickly, I thought) modelled how to auscultate her heart sounds and had not completely replaced the patient's gown. Her husband looked on from the corner of the room, disapproving of our nervousness and hesitance, or so I imagined. And if he did, it was with good reason. Some of us had not even purchased all of our supplies yet and had to borrow them from a classmate. Others

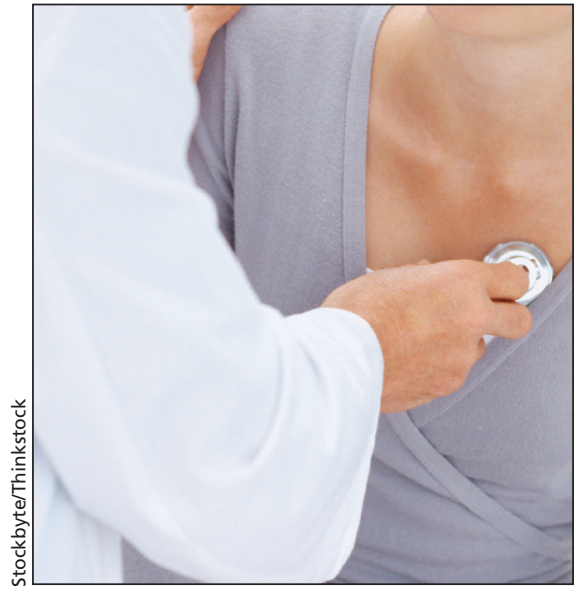

had never spoken to a patient before. None of us knew how to use our stethoscopes. Or how to approach a patient's physical exam with dignity.

One by one, we crossed the distance that separated the patient's bed from the wall where we were all huddled, introduced ourselves, fumbled with our earpieces, worried about where to put the diaphragm of the instrument, whether we were actually hearing anything or just imagining it, how far we should displace the gown, what was the appropriate way to move her breast -

I was second in line. Some time to plan what I was going to say and how I was going to act. Some time to collect myself. Some time to put on the face of someone braver and smarter and older than I was. A minute, a few seconds in between my classmate's attempt and mine. Really, no time at all. Silence. A "Hello," a few instructions, a light pressure. Hand on shoulder. Metal on skin.

Heartbeats.

\section{Bob Sun BA}

Cleveland Clinic Lerner College of Medicine, Case Western Reserve

University, Cleveland, Ohio

CMAJ 2016. DOI:10.1503/cmaj.150291 